\title{
SINTESIS DAN KARAKTERISASI MATERIAL BERPORI BERBASIS MINERAL SILIKA PULAU BELITUNG
}

\author{
Synthesis and Characterization of Porous Material Based on the \\ Belitung-Island Silica Mineral
}

\author{
AZHARI dan MUCHTAR AZIZ \\ Puslitbang Teknologi Mineral dan Batubara \\ Jalan Jend. Sudirman 623 Bandung 40211 \\ Telp. (022) 6030483, Fax. (022) 6003373 \\ e-mail: azhari@tekmira.esdm.go.id
}

\begin{abstract}
ABSTRAK
Dalam rangka pembuatan membran penyaring molekul, khususnya untuk penggunaan dalam peningkatan kadar bioetanol, telah dilakukan serangkaian percobaan pembentukan material silika berpori dengan metoda sol-gel, berbasis mineral silika asal P. Belitung. Pertama-tama mineral silika ditingkatkan kadar silikanya melalui operasi penggerusan dan pelindian dengan variasi jenis asam. Selanjutnya silika hasil pelindian disaring dan dicuci dengan akuades sehingga bebas asam, kemudian dikeringkan. Silika kering yang telah berkadar tinggi $\left(99,42 \% \mathrm{SiO}_{2}\right)$, selanjutnya diproses melalui garam lebur soda kostik pada suhu tinggi, untuk mendapatkan senyawa sodium silikat yang larut dalam air. Larutan sodium silikat dipisahkan dari residunya dan dipresipitasi dengan asam untuk memperoleh endapan halus, berupa silika gel $\left(\mathrm{SiO}_{2} \cdot \mathrm{xH}_{2} \mathrm{O}\right)$. Selanjutnya silika gel dicuci sehingga bebas garam, dipreparasi dan dikarakterisasi. Hasil karakterisasi menunjukkan terbentuknya $\mathrm{SiO}_{2}$ halus berukuran nano, yang dapat mencapai ukuran terkecil 96,9 nm. Hasil pengamatan SEM, nampak dalam foto mikrograf tekstur material berpori; dan hasil analisis BET menunjukkan luas permukaan spesifik mencapai $180 \mathrm{~m}^{2} / \mathrm{g}$.
\end{abstract}

Kata kunci : pasir silika, sol-gel, material berpori.

\begin{abstract}
In order to make a molecular membran especially for using in the bioethanol purification, a series of the experiments of formation silica porous material, with a sol-gel method, based of silica mineral from Belitung Island had been conducted. First of all, silica mineral samples from the field must be improved its silica contents through grinding and leaching operations with various kinds of acid. Subsequently the silica was filtered and washed with aquadest so that leached product was acid free, and then it was dried. Dried silica having higher levels of silica content $\left(99,42 \% \mathrm{SiO}_{2}\right)$ was then processed through a high temperature of molten salt caustic soda, to get the compounds of sodium silicate soluble in water. A solution of sodium silicate was separated from the residue, and clear solution was then precipitated with acid to obtain fine particles in the form of silica gel $\left(\mathrm{SiO}_{2} . \mathrm{xH}_{2} \mathrm{O}\right)$. The next, silica gel was washed so that it was free of salt content, the product was then prepared and characterized. Characterization results shows the formation of silica nano particles, which reached the smallest size of $96,9 \mathrm{~nm}$. Photo micrograph of SEM shows the texture of porous material, analysis of BET shows a specific surface area of $180 \mathrm{~m}^{2} / \mathrm{g}$.
\end{abstract}

Keywords : silica sand, sol-gel, porous material. 


\section{PENDAHULUAN}

Silika atau kuarsa (quartz) merupakan mineral yang jumlahnya melimpah di permukaan kerak bumi, mempunyai rumus kimia $\mathrm{SiO}_{2}$, dan memiliki sifat menonjol, yaitu kekerasannya yang tinggi (7 pada skala Mohs), serta sangat tahan terhadap asam. Silika paling banyak ditemukan di alam dalam bentuk pasir, sering disebut pasir silika atau pasir kuarsa. Silika di alam berasal dari batuan beku (igneous rocks) dan batuan metamorf (metamorphic rocks) yang dihancurkan oleh proses pelapukan (weathering process), mengalami transportasi dan pengendapan [Bergaya et.al., 2006]. Disamping menghasilkan silika, pada proses pelapukan juga terjadi erosi, transportasi, dan pengendapan hasil pelapukan di danau, laut, dan lautan, mendorong terbentuknya material silikat berukuran lempung (clay-sized material) seperti haloysit, kaolinit, bentonit, illit, dan lain-lain.

Selama ini pasir silika sudah banyak dimanfaatkan untuk berbagai keperluan dengan berbagai spesifikasi dan ukuran partikel tergantung aplikasinya seperti dalam industri pengecoran, ban, karet, plastik, gelas, semen, beton, keramik, amplas, sand blast, dan lain-lain. Di negara-negara maju, penelitian pemanfaatan pasir silika saat ini sudah jauh berkembang, diantaranya ditujukan untuk pembuatan silika spesial seperti silika gel, presipitat, silika asap dan koloid. Pasar global silika spesial diperkirakan mencapai nilai 1.7 juta USD [Sirivasta, et.al., 2013], dan diperkirakan mencapai laju pertumbuhan sekitar $4 \%$ pertahun. Silika presipitat berkemurnian tinggi (highly purified precipitated silica) juga telah digunakan secara luas, meliputi untuk memproduksi nano material diantaranya membran nano silika, memperkuat karet dan plastik, mengentalkan bahan pelapis dan cat, tinta cetak, plastik dan kosmetik, sebagai pengering, penstabil, penyerap, pengental makanan, serta sebagai pembawa pestisida dan katalis.

Sifat kekerasan dan ketahanan terhadap asam yang dimiliki silika, menyebabkan material ini menjadi salah satu pilihan sebagai media filter karena tahan terhadap abrasi dan $\mathrm{pH}$ asam, terutama dalam proses filtrasi.
Pemurnian bioetanol dengan cara distilasi yang telah dilakukan selama ini memiliki kelemahan karena campuran air dan etanol dapat membentuk azeotrope, yaitu kondisi dimana air dan etanol tidak dapat dipisahkan lagi dengan cara distilasi biasa sehingga kemurnian etanol sulit ditingkatkan lagi. Kondisi ini dicapai pada fraksi mol etanol $89 \%$. Selain itu, cara distilasi memiliki kelemahan pada efisiensi energi yang rendah, membutuhkan energi yang besar dan menghasilkan emisi karbondioksida. Pemurnian bioetanol dengan menggunakan membran bisa menjadi solusi. Metode ini dapat menghasilkan etanol dengan kemurnian tinggi ( $>95 \%)$. Penggunaan membran berbasis mineral silikat atau aluminosilikat seperti pasir silika dan zeolit sudah dikembangkan di beberapa negara di dunia, diantaranya di Brazil [Carlo et.al, 2011]. Membran yang terbuat dari silika memiliki sifat permeselektivitas terhadap etanol, yakni hanya melewatkan molekul etanol. Lapisan silika mesopori telah dicoba dibuat atau dibentuk pada tube alumina berpori (yang sudah dijual dipasaran) dengan cara dipcoating dalam suatu seri silika sol, yang kemudian diperkuat dengan modifikasi bahan organik [Jin et.al., 2011]. Hasilnya telah menunjukkan adanya selektivitas melewatkan molekul etanol (ethanol permselectivity) dan peningkatan aliran dengan bertambahnya konsentrasi etanol dalam feed.

Penelitian material silika berpori selama ini telah dilakukan oleh beberapa peneliti terdahulu, diantaranya melalui ekstraksi silika murni dari perlit, melalui kalsinasi dan pelarutan dengan larutan alkali serta pengendapan dengan asam [Sirivasta, et.al., 2013]. Hasilnya menunjukkan telah memperoleh silika presipitat halus dengan kemurnian 70,6\% $\mathrm{SiO}_{2}$, memiliki luas area spesifik $98 \mathrm{~m}^{2} / \mathrm{g}$, dan ukuran partikel 0.3-1 $\mu \mathrm{m}$ atau 300-1.000 nm. Kemudian juga dari bahan baku pasir zirkon, melalui alkali fusion, pelarutan dengan air, dan pengendapan dengan asam, diperoleh presipitat halus zirkonia dan pasir silika berkemurnian tinggi [Yamagata et.al., 2010]. Hasilnya menunjukkan diperoleh zirkonia halus berkadar 87,26\% $\mathrm{ZrO}_{2}$, luas area spesifik 72,29 $\mathrm{m}^{2} / \mathrm{g}$; dan diperoleh presipitat silika halus berkadar 99,51\% $\mathrm{SiO}_{2}$, luas area spesifik $501,32 \mathrm{~m}^{2} / \mathrm{g}$. Nano partikel silika amorf telah diekstraksi dari batu apung (pumice) melalui 
rute pelindian dengan soda kostik serta presipitasi dengan asam, menghasilkan struktur silika berpori amorf, mempunyai luas area spesifik $422 \mathrm{~m}^{2} / \mathrm{g}$ serta ukuran partikel silika sangat halus mencapai 5-15 nm [Asmaa et.al., 2015]. Silika amorf juga telah disintesis menggunakan sodium silikat dan presipitasi dengan asam khlorida mengikuti metoda Stőber. Sistem reaksi kimia presipitasi telah dikembangkan untuk mengontrol pertumbuhan partikel silika menggunakan dua jenis cationic surfactant berbeda sebagai pendispersi, yaitu cetyltrimethylammonium bromida (CTAB) dan dodecyltrimethylammonium bromida (DTAB). Hasilnya menunjukkan diperolehnya nano partikel silika amorf dengan kehalusan 148-212 nm [Rida dan Harb, 2014]. Penggunaan nano partikel silika sebagai bahan pengisi dalam pembuatan polimer nano komposit telah menarik banyak perhatian, disebabkan meningkatnya kebutuhan material baru (new materials) dengan perbaikan sifat-sifat termal, mekanikal, fisikal, dan kemikal [Rahman and Padavettan, 2012].

Penelitian penyiapan nano partikel silika sudah dilakukan pada tahun 2011 di Puslitbang tekMIRA. Penyiapan nano partikel silika dilakukan melalui cara mekanis (penggerusan) dengan alat Planetary ball Mill; dan alkali fusion; hasilnya terutama ditujukan untuk aditif beton, berukuran partikel $80 \mathrm{~nm}$ [Wahyudi dkk., 2011].

Penelitian ini bertujuan untuk menghasilkan material berpori berbasismineral silika asal P. Belitung,serta karakterisasinya; sebagai bahan dasar untuk membran silika. Dasar penggunaan mineral silika asal $\mathrm{P}$. Belitung, karena memiliki kadar 97,1\% $\mathrm{SiO}_{2}$. Kadar atau kemurnian yang tinggi dari mineral silika sebagai bahan baku amat penting diperhatikan, karena akan berhubungan dengan homogenitas partikel nanosilika berpori yang dihasilkan. Material nanosilika berpori yang dihasilkan ditujukan untuk pembuatan membran nanosilika, khususnya untuk pemurnian bioetanol.

\section{METODE}

Pembentukan material silika berpori berpartikel skala nano ini, dilakukan dengan metode sol-gel [Jafari and Allahverdi, 2014].
Sampel mineral silika yang digunakan dalam penelitian ini diambil dari tempat penambangan dan pencucian pasir silika di P. Belitung. Sampel yang diambil sudah mengalami proses konsentrasi menggunakan hidrosiklon sehingga kandungan silika dalam pasir (head sample) sudah relatif tinggi. Head sample dianalisis kimia dengan atomic absorption spectrophotometer (AAS).

Selanjutnya head sample dipreparasi di Lab. tekMIRA sebagai berikut : penggerusan menggunakan ceramic ball mill serta pengayakan (sieving) menggunakan ayakan berukuran 200 mesh. Semua pasir digerus sampai lolos ayakan 200 mesh. Ukuran partikel pasir yang lolos ayakan 200 mesh tersebut yang akan digunakan dalam percobaan. Sampel pasir silika hasil preparasi dianalisis kimia dengan AAS.

Identifikasi mineral dalam sampel tergerus dilakukan dengan x-ray diffraction (XRD), distribusi elemen dan morfologi mineral dianalisis dengan scanning electron microscope-energy disversive x-ray analysis (SEM-EDX).

Setelah karakterisasi, pasir silika tergerus diambil percontoh untuk dilakukan proses pelindian, dengan variasi jenis asam pelarut pengotor, yaitu : asam klorida, asam sulfat, dan asam nitrat untuk mengetahui penggunaan jenis asam yang lebih tepat. Proses pelindian untuk melarutkan pengotor dilakukan dalam asam konsentrasi 10\% berat, persen solid 20\%, waktu pelindian 2 jam pada suhu kamar. Hasil pelindian selanjutnya disaring, residunya dicuci sampai bebas asam dan dikeringkan.

Pasir silika kering berkemurnian tinggi selanjutnya diproses dengan garam lebur soda kostik (alkali fusion) dalam muffle furnace, untuk membentuk senyawa sodium silikat yang mudah larut dalam air. Perbandingan berat $\mathrm{NaOH}$ dan silika, $\mathrm{NaOH} /$ Silika1,5 [Yamagata et.al., 2010]. Suhu divariasi,dari $500-900^{\circ} \mathrm{C}$; yaitu 500, 600, 700, 800, dan $900^{\circ} \mathrm{C}$ dengan waktu masing-masing selama 2 jam. Hasil alkali fusion didinginkan dalam desikator, digerus [Yilmaz and Piskin, 2013]. Hasil penggerusan dilindi dengan air untuk melarutkan sodium silikat, dan disaring, menghasilkan filtrat berupa larutan jernih 
sodium silikat, dan residu pengotor diatas saringan. Filtrat dipresipitasi menggunakan asam khlorida $8 \mathrm{M}$, presipitat berupa endapan halus silika disaring, dicuci dengan akuades sampai bebas garam [Yamagata et.al., 2010]. Selanjutnya endapan halus silika dikarakterisasi. Bagan alir percobaan ditunjukkan pada Gambar 1.

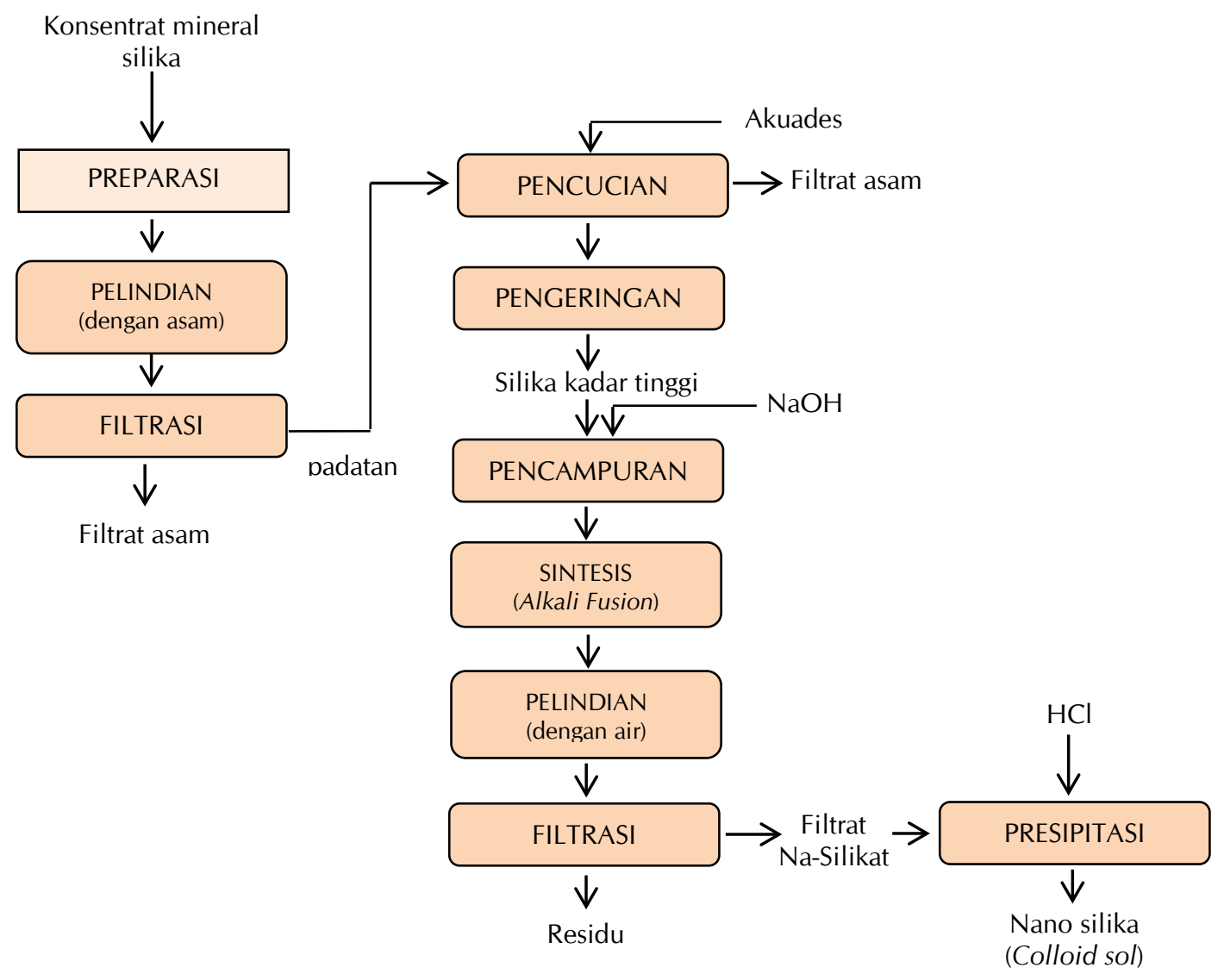

Gambar 1. Bagan alir pengerjaan sampel dan pemrosesan pasir silika

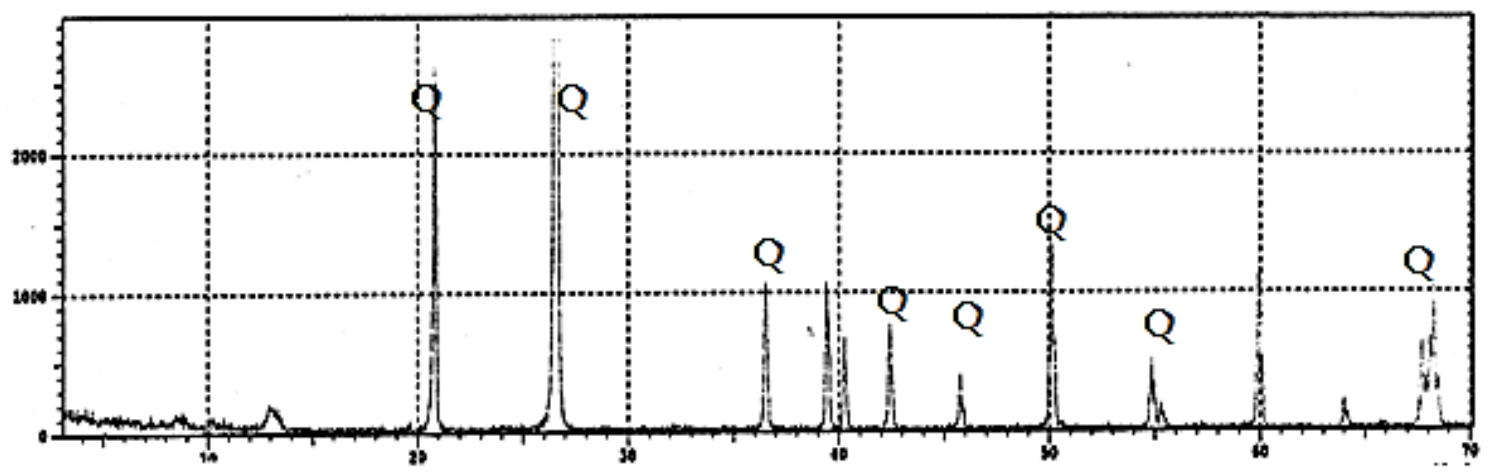

Gambar 2. Difraktogram sampel pasir silika menunjukkan puncak kuarsa (Q) 


\section{HASIL DAN PEMBAHASAN}

\section{Karakterisasi bahan baku}

Hasil analisis XRD sampel pasir silika ditunjukkan pada Gambar 2. Tampak puncakpuncak pada difraktogram menunjukkan kristal-kristal kuarsa atau silika (Quartz, Q), sementara mineral-mineral lainnya tidak tampak. Dari hasil analisis XRD tersebut dapat dipastikan sampel pasir yang didapat dari $\mathrm{P}$. Belitung adalah pasir kuarsa.

Hasil foto mikrograf pada head sample pasir silika ditunjukkan pada Gambar 3. Nampak butiran silika didominasi butiran-butiran bersudut tajam (angular) yang menunjukkan pasir silika tidak mengalami transportasi yang jauh, sehingga diharapkan unsur-unsur yang mengotorinya relatif sedikit.

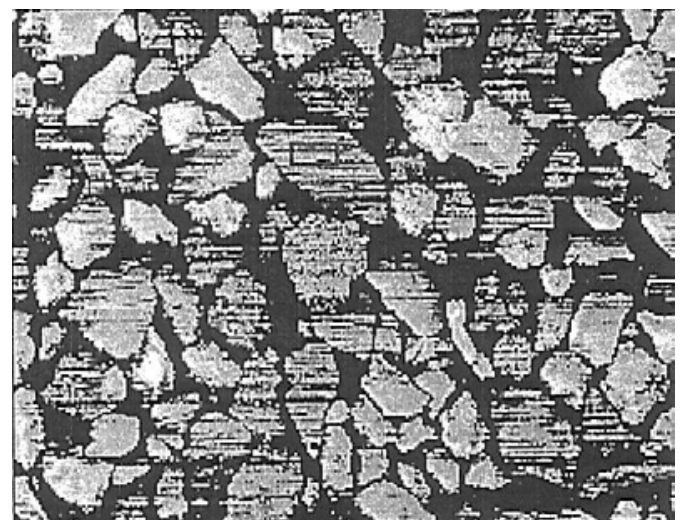

Gambar 3. Foto mikrograf head sample pasir silika

Hasil EDAX head sample pasir silika ditunjukkan pada Gambar 4. Pada pengamatan spot partikel kuarsa, maka unsur-unsur utama (mayor elements) adalah $\mathrm{Si}$ dan $\mathrm{O}$, dengan kuantitas unsur Si sebesar 50,65\% dan O sebesar $46,61 \%$, data ini berkesesuaian dengan data X-RD. Unsur-unsur minor yaitu Sn 2,24\%, Al 0,46\%, K 0,05\%, dan Ca menunjukkan 0\%. Unsur-unsur minor tersebut umumnya berpotensi dapat dilarutkan dengan asam mineral (mineral acid).

Komposisi kimia sampel pasir silika dari lapangan (head sample) ditunjukkan pada Tabel 1.
Tabel 1. Komposisi kimia sampel pasir silika (head sample)

\begin{tabular}{cc}
\hline & $\%$ \\
\hline $\mathrm{SiO}_{2}$ & 97,1 \\
$\mathrm{Al}_{2} \mathrm{O}_{3}$ & 0,11 \\
$\mathrm{Fe}_{2} \mathrm{O}_{3}$ & 0,075 \\
$\mathrm{~K}_{2} \mathrm{O}$ & 0,022 \\
$\mathrm{Na} 2$ & 0,11 \\
$\mathrm{CaO}$ & 2,06 \\
$\mathrm{MgO}$ & 0,046 \\
$\mathrm{TiO}_{2}$ & $<0,001$ \\
$\mathrm{P}_{2} \mathrm{O}_{5}$ & $<0,001$ \\
$\mathrm{Cr}_{2} \mathrm{O}_{3}$ & $<0,001$ \\
$\mathrm{SnO}_{2}$ & $<0,001$ \\
$\mathrm{LOI}$ & 0,41 \\
\hline
\end{tabular}

Berdasarkan data di atas tampak bahwa pasir silika sebagai bahan baku berkualitas baik, dengan kadar silika 97,01\% sehingga memudahkan proses selanjutnya, terutama dalam mengurangi kandungan unsur-unsur pengotornya. Meskipun demikian, tahapan pelindian untuk melarutkan unsur-unsur pengotor tetap dilakukan, agar diperoleh hasil dengan kualitas yang optimal.

\section{Pelindian dengan asam}

Hasil analisis X-RF residu hasil pelindian dengan berbagai asam ditunjukkan pada Tabel 2. Nampak bahwa pelarut asam sulfat menunjukkan hasil yang lebih baik dibandingkan dengan asam yang lain dalam melarutkan pengotor pada pasir silika.

\section{Sintesis dengan garam lebur alkali dan presipitasi nanosilika}

Pasir silika dicampur dengan $\mathrm{NaOH}$ flakes sehingga merata. Sintesis berlangsung dalam krusibel di dalam muffle furnace, membentuk senyawa sodium silikat $\left(\mathrm{Na}_{2} \mathrm{O} \cdot \mathrm{SiO}_{2}\right)$ menurut reaksi kimia sebagai berikut [Manjula et.al., 2014 ]:

$\mathrm{SiO}_{2}+2 \mathrm{NaOH} \rightarrow \mathrm{Na}_{2} \mathrm{O}_{2} \mathrm{SiO}_{2}+\mathrm{H}_{2} \mathrm{O}$

Sodium silikat hasil alkali fusion dilindi dengan air [Yamagata et.al., 2010] sehingga larut menjadi larutan sodium silikat menurut reaksi :

$\mathrm{Na}_{2} \mathrm{O} \cdot \mathrm{SiO}_{2}+\mathrm{nH}_{2} \mathrm{O} \rightarrow \mathrm{Na}_{2} \mathrm{O} \cdot \mathrm{SiO}_{2} \cdot \mathrm{nH}_{2} \mathrm{O}$ 


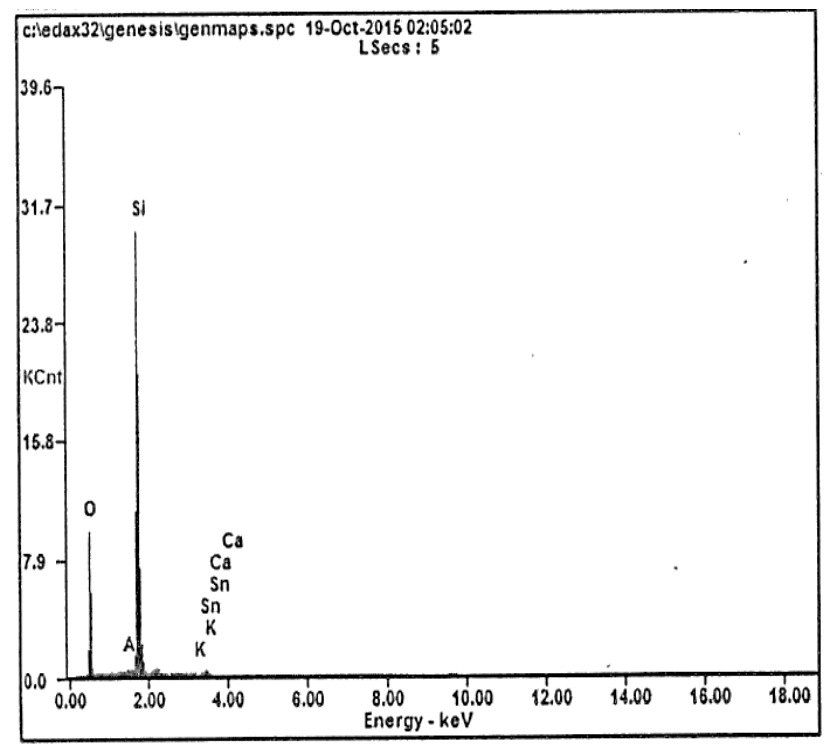

\begin{tabular}{lll}
\hline Element & $\mathrm{Wt} \%$ & $\mathrm{At} \%$ \\
\hline OK & 46,61 & 62,28 \\
AIK & 00,46 & 00,36 \\
SiK & 50,65 & 37,94 \\
KK & 00,05 & 00,03 \\
SnL & 02,24 & 00,40 \\
CaK & 00,00 & 00,00 \\
Matrix & Correction & ZAF \\
\hline
\end{tabular}

Gambar 4. Hasil EDAX head sample pasir silika

Tabel 2. Hasil analisis XRF residu hasil pelindian dengan beberapa jenis asam

\begin{tabular}{lccccc}
\hline \multicolumn{1}{c}{ Analisis } & Unit & Head sample & Asam sulfat & Asam klorida & Asam nitrat \\
\hline $\mathrm{SiO}_{2}$ & $\%$ & 97,1 & 99,42 & 98,67 & 98,78 \\
$\mathrm{Al}_{2} \mathrm{O}_{3}$ & $\%$ & 1,35 & $<0,01$ & $<0,01$ & $<0,01$ \\
$\mathrm{Fe}$ (tot) & $\%$ & 0,05 & $<0,01$ & $<0,01$ & $<0,01$ \\
$\mathrm{Fe} 2 \mathrm{O}_{3}$ & $\%$ & 0,07 & $<0,01$ & $<0,01$ & $<0,01$ \\
$\mathrm{CaO}$ & $\%$ & 0,29 & 0,01 & 0,01 & 0,03 \\
$\mathrm{MnO}$ & $\%$ & 0,02 & 0,01 & 0,01 & 0,01 \\
$\mathrm{MgO}$ & $\%$ & 0,03 & 0,01 & 0,01 & 0,02 \\
$\mathrm{~K} 2 \mathrm{O}$ & $\%$ & 0,68 & $<0,01$ & 0,01 & $<0,01$ \\
$\mathrm{Na}_{2} \mathrm{O}$ & $\%$ & 0,37 & 0,35 & 0,35 & 0,35 \\
$\mathrm{P}_{2} \mathrm{O}_{5}$ & $\%$ & $<0,01$ & $<0,01$ & $<0,01$ & $<0,01$ \\
$\mathrm{Cr}_{2} \mathrm{O}_{3}$ & $\%$ & 0,02 & 0,03 & 0,06 & 0,05 \\
$\mathrm{TiO}_{2}$ & $\%$ & 0,46 & 0,12 & 0,12 & 0,13 \\
$\mathrm{LOI}$ & $\%$ & 0,48 & 0,11 & 0,86 & 0,29 \\
\hline
\end{tabular}

Pelarutan sodium silikat dengan air menyisakan residu pengotor, yang kemudian dipisahkan dengan saringan. Gambar 5. menunjukkan penampakkan material hasil sintesis dengan alkali fusion (A) dan larutan hasil pelindian dengan air (B).

Hasil pelindian selanjutnya disaring, sehingga diperoleh filtrat larutan sodium silikat yang jernih, serta residu pengotor diatas saringan.

Presipitasi silika dilakukan dengan cara meneteskan larutan $\mathrm{HCl} 8 \mathrm{M}$ pada larutan jernih sodium aluminat sehingga tercapai $\mathrm{pH}$ 7 [Yamagata et.al., 2010]. Pada presipitasi silika terjadi reaksi penetralan basa dengan asam menurut reaksi kimia sebagai berikut :

$$
\begin{aligned}
& \mathrm{Na}_{2} \mathrm{O} . \mathrm{SiO}_{2} \cdot \mathrm{nH}_{2} \mathrm{O}+2 \mathrm{HCl} \rightarrow \\
& \mathrm{SiO}_{2}+\downarrow 2 \mathrm{NaCl}+\mathrm{n} 2 \mathrm{H}_{2} \mathrm{O}
\end{aligned}
$$

Hasil reaksi tersebut memperoleh endapan silika halus berupa gel (silica gel), yang mempunyai rumus kimia $\mathrm{SiO}_{2} \cdot \mathrm{xH}_{2} \mathrm{O}$ sebagai padatan amorf [Fathi, 1997]. Gambar 6. menunjukkan foto proses presipitasi dalam sebuah labu $(\mathrm{P})$, presipitat kemudian disaring dan dicuci diatas saringan dengan akuades sampai bebas garam. Diperoleh presipitat silika halus diatas saringan (Q). Selanjutnya presipitat silika dikarakterisasi. 


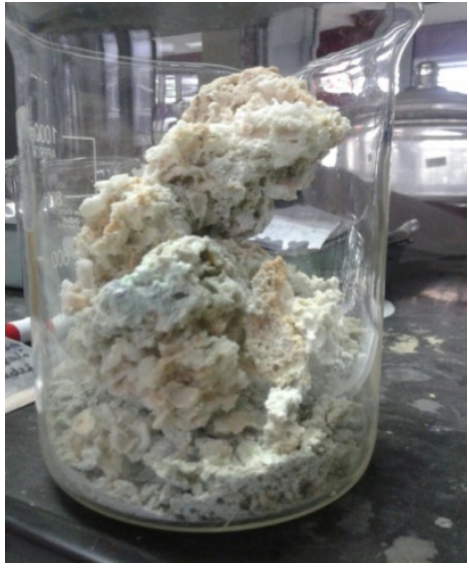

A

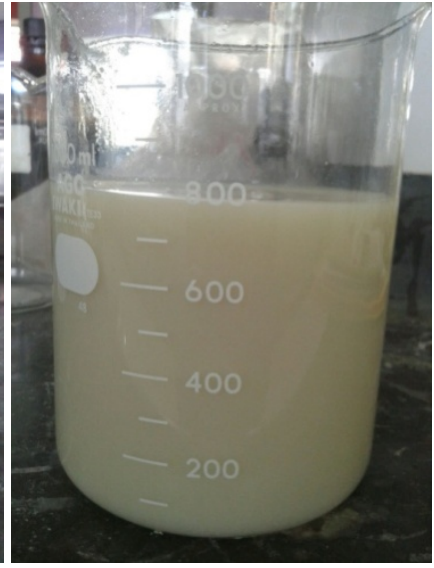

B

Gambar 5. Hasil sintesis dengan alkali fusion(A) dan larutan hasil pelindian dengan air (B)

\section{Karakterisasi material berpori}

Partikel nanosilika hasil percobaan kemudian dianalisis dengan particle size analyzer (PSA) untuk mengetahui ukuran dan distribusi ukuran partikelnya. Hasil analisis ditampilkan pada tabel berikut.

Tabel 3. Ukuran partikel nano silika

\begin{tabular}{cc}
\hline Suhu $\left({ }^{\circ} \mathrm{C}\right)$ & Ukuran partikel $(\mathrm{nm})$ \\
\hline 500 & 416,2 \\
600 & 260,4 \\
700 & 450,0 \\
800 & 96,9 \\
900 & 392,8 \\
\hline
\end{tabular}

Dari hasil tersebut di atas terlihat bahwa ukuran partikel berfluktuasi pada kenaikan temperatur proses alkali fusion, namun kecenderungannya mengalami penurunan pada interval suhu $500-800^{\circ} \mathrm{C}$. Hal ini kemungkinan disebabkan oleh ketidaksempurnaan pada proses presipitasi yang menyebabkan laju pertumbuhan butir partikel belum sepenuhnya terkontrol dengan baik. Proses presipitasi perlu disempurnakan lagi, terutama pada perlakuan awal sebelum presipitasi, laju penambahan asam khlorida dan kecepatan putaran pengaduk. Dari data di atas, hasil yang optimal adalah pada suhu $800^{\circ} \mathrm{C}$ dengan ukuran partikel 96,9 nm. Untuk melihat bentuk serta tekstur partikel telah dilakukan pengamatan melalui SEM pada sampel nano silika kering. Gambar 7. menunjukkan foto-foto SEM pada perbesaran 500x dan 1500x.
Pada perbesaran 3000x (Gambar 8) terlihat lebih jelas struktur partikel-partikel berpori. Dengan ukuran partikel berskala nano, maka partikel-partikel tersebut memiliki nano pori. Karakteristik inilah yang diharapkan berpotensi untuk pembuatan material membran penyaring molekul (mesoporous). Makin kecil ukuran partikel dan berpori, maka luas permukaan spesifik (specific surface area, SSA) juga semakin besar. Hasil analisis BET menunjukkan luas permukaan mencapai $180 \mathrm{~m}^{2} / \mathrm{g}$. Angka SSA mencerminkan banyaknya pori suatu material, lebih tinggi angka SSA, maka material lebih porous.

Hasil yang diperoleh dari penelitian ini menunjukkan angka SSA lebih tinggi jika dibandingkan dengan hasil peneliti terdahulu [Sirivasta, 2013] yang angka SSA-nya hanya $98 \mathrm{~m}^{2} / \mathrm{g}$, dengan menggunakan perlit sebagai bahan baku, serta pemrosesannya melalui jalur: kalsinasi-pelarutan dengan alkali dan presipitasi dengan asam; demikian pula kadar material berpori yang dihasilkan penelitian ini lebih murni, mencapai 99,42\% $\mathrm{SiO}_{2}$, jauh lebih tinggi dari hasil penelitian terdahulu yang hanya mencapai $70,6 \% \mathrm{SiO}_{2}$. Disamping itu penelitian ini juga telah menghasilkan partikel silika yang jauh lebih halus, yaitu 96,9 nm, dibanding dengan penelitian sebelumnya yang hanya mencapai $300 \mathrm{~nm}$. Namun jika dibandingkan dengan hasil penelitian terdahulu yang menggunakan pasir zirkon sebagai bahan baku, serta pemrosesan melalui jalur yang sama dengan penelitian ini; angka kadar material berpori hasil penelitian terdahulu berada sedikit diatas, yaitu $99,51 \% \quad \mathrm{SiO}_{2}$; dan hasil 
angka SSA penelitian terdahulu jauh lebih tinggi, mencapai 2,8 kalinya, yaitu 501,32 $\mathrm{m}^{2} / \mathrm{g}$, menunjukkan material yang dihasilkan sangat porous. Hasil evaluasi terhadap perbedaan yang jauh ini, kemungkinannya adalah pada teknik presipitasi dan pencuciannya. Pada teknik presipitasi melibatkan beberapa variabel, antara lain waktu (kecepatan) pengendapan, putaran pengadukan, suhu, dan konsentrasi asam. Pada teknik pencuciannya, yang terpen-ting adalah bebas garam, karena sisa garam berpotensi menutup pori-pori pada saat penge-ringan dan kalsinasi.

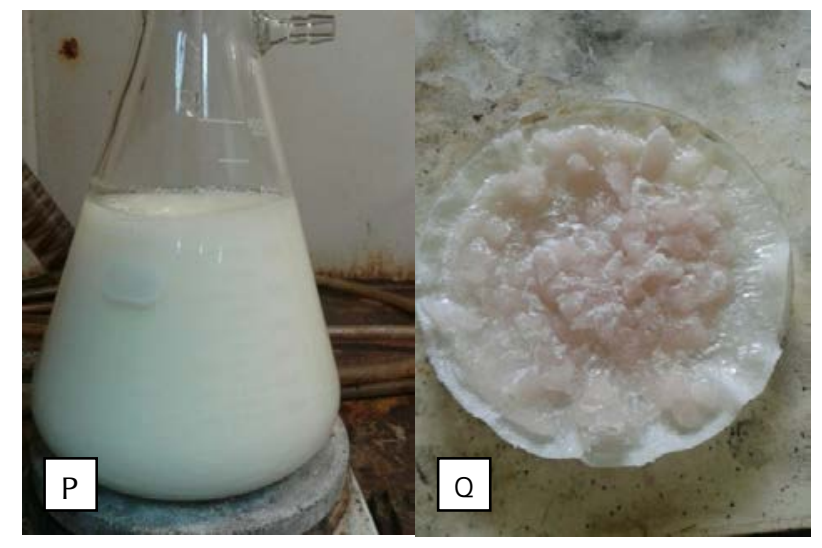

Gambar 6. Proses presipitasi (P) dan presipitat berupa silika gel yang terbentuk (Q)
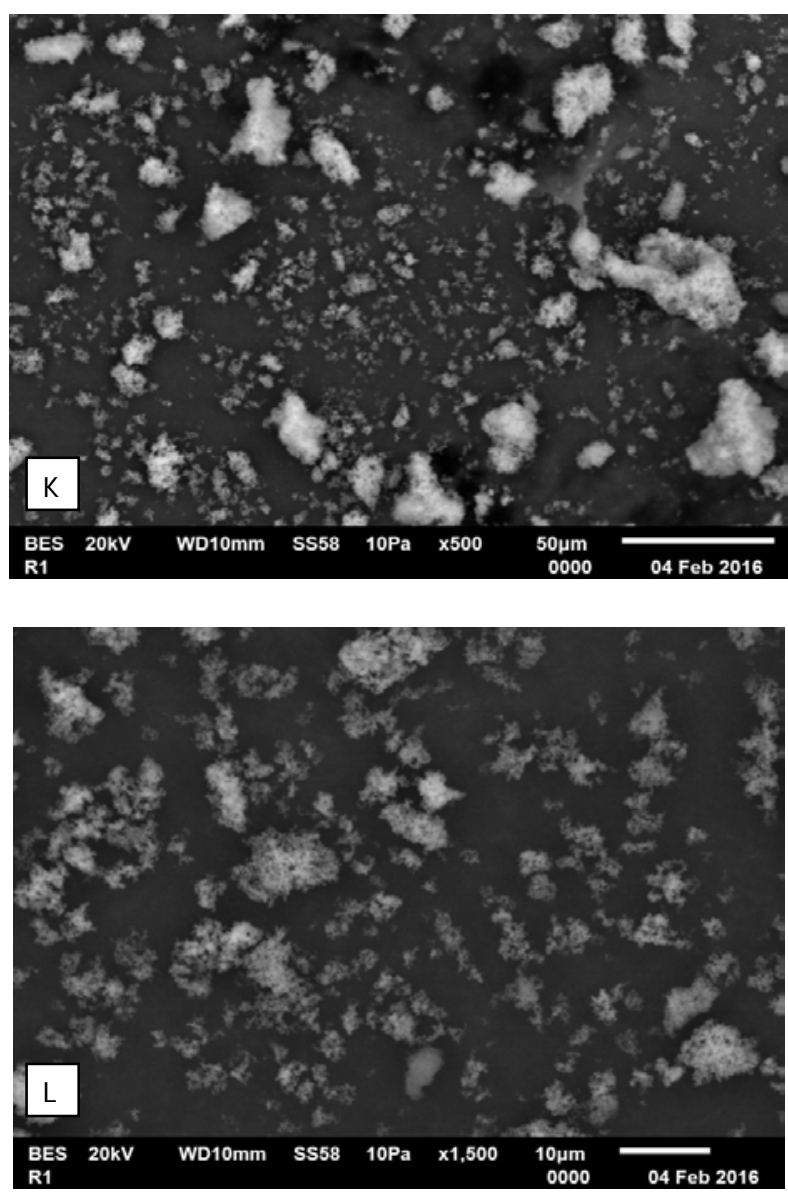

Gambar 7. Foto SEM sampel nanosilika dengan perbesaran500x (K) dan 1500x (L) 


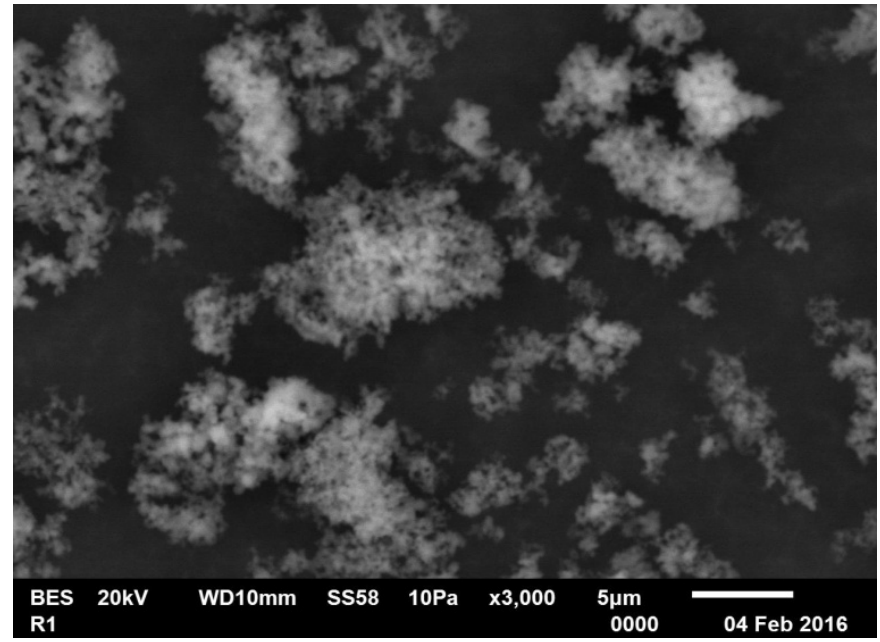

Gambar 8. Foto SEM sampel nanosilika dengan perbesaran 3000x

\section{KESIMPULAN}

Berbasis pada konsentrat pasir silika sebagai bahan baku, melalui metode pelindian dengan asam sulfat, sintesis dengan garam lebur alkali, serta proses pelarutan dan presipitasi dengan asam, dapat dihasilkan partikel-partikel silika yang sangat halus. Hasil karakterisasi menunjukkan partikel-partikel nanosilika berukuran 96,9 nm. Hasil pengamatan SEM menunjukkan fotomikrograf tekstur material berpori. Hasil analisis BET menunjukkan luas permukaan spesifik mencapai $180 \mathrm{~m}^{2} / \mathrm{g}$. Kondisi pemrosesan awal telah menghasilkan material nano silika, namun masih perlu disempurnakan pada proses presipitasi, pencucian, dan kalsinasi untuk mencapai penyaring molekuler (mesoporous).

\section{UCAPAN TERIMA KASIH}

Terima kasih yang sebesar-besarnya atas terlaksananya penelitian pembuatan material silika berpori ini disampaikan kepada semua pihak yang telah membantu; para teknisi di KP3-Mineral, khususnya Pak Jejen, Teknisi Litkayasa, baik sejak pengambilan percontoh di lapangan maupun dalam pelaksanaan pemrosesan di Lab. tekMIRA; juga Pak Tatang Wahyudi, Peneliti Utama, atas bantuan pengamatan SEM; Koordinator KP3-Mineral atas koordinasi pelaksanaan penelitian; serta dukungan Kapuslitbang tekMIRA, khususnya dalam pendanaan penelitian. Terima kasih juga disampaikan kepada para staf dan editor Jurnal Teknologi Mineral dan Batubara atas sumbangsihnya pada penerbitan karya tulis ilmiah ini.

\section{DAFTAR PUSTAKA}

Asmaa M., Mariam K., Adnane El H., M. Kacimi, M. Halim, and Said A., 2015. The synthesis and characterization of low-cost mesoporous silica $\mathrm{SiO}_{2}$ from local pumice rock, Laboratory of Materials, Catalysis and Environment (CNRST-URAC 26), University of Mohammed V, Faculty of Sciences, Rabat, Morocco, hal. 5-6.

Bergaya F., Theng B.K.G. Lagaly G., 2006. Handbook of clay science, First Ed., Elsevier, Oxford OX5 1GB, UK, 1129 hal.

Carlos Basso L., Olitta Basso T., and Saul Nitsche Rocha, 2011. Ethanol production in Brazil : The industrial process and its impact on yeast fermentation, University of Sao Paulo; Positivo University, Brazil, hal. 91-92.

Fathi, H., 1997. Handbook of extractive metallurgy, ferroalloy metals, silicon, 1861 hal., Willey-VCH, ISBN 3-527-28792-2, Toronto, Canada.

Jafari, V., and Allahverdi, A., 2014. Synthesis of nanosilica from silica fume using an acid-base precipitation technique and PVA as a nonionic surfactant, Journal of Ultrafine Grained and Nanostructured Materials, Vol.47, No.2, Dec 2014, hal.105-106. 
Jin, T., Ma, Y., Matsuda, W., Masuda, Y., Nakajima, M., Ninomiya, K., Hiraoka, T. Daiko, Y. and Yazawa, T., 2011. Ethanol separation from ethanol aqueous solution by pervaporationusing hydrophobic mesoporous silica membranes, Journal of Ceramic Society of Japan, 119 [7]549-556, hal. 139-141.

Manjula Rani K., Palanisamy P.N., Sivakumar P., 2014. Synthesis and characterization of amorphous nano-silica from biomass ash, ljates, Vol. 02, Issue no.10, ISSN: 2348-7550, hal.71-72.

Rahman, I.A. and Padavettan, V., 2012. Synthesis of silica nanoparticles by sol-gel: Sizedependent properties, surface modification, and aplications in silica-polymer nanocomposites - A review, Journal of Nanomaterials, Malaysia, Vol. 2012 (2012), hal.1-2.

Rida, M.A. and Harb, F., 2014. Synthesis and characterization of amorphous silica nanoparticles from aqueous silicates using cationic surfactants, pp. 37-41, Laboratory of Molecular Chemistry and Solid State
Reactivity, Lebanese University, Faculty of Sciences II, Fanar, Lebanon.

Srivasta, K., Shringi, N., Devra, V., and Rani, A., 2013. Pure silica extraction from perlite: Its characterization and affecting factors, IJIRSET, Vol.2, Issue 7, July 2013, hal. 2936-2937.

Wahyudi, A., Amalia, D., Maryono, Saleh, N., Purnomo, H., Rochani, S., dan Ardha, N., 2011. Penyiapan nanopartikel silika dari mineral silikat secara mekanis, hal. 29, Puslitbang tekMIRA.

Yamagata, C., Andrade, J.B., Ussui, V., Lima, N.B. and Paschoal, J.O.A., 2010. High purity zirconia and silica powders via wet process: Alkali Fusion of Zircon Sand, Sixth International Latin-American Conference on Powder Technology, November 07-10, Búzios, Rio de Janeiro, Brazil, hal. 772-773.

Yilmaz, M.S. and Piskin, S., 2013. Extraction of silicon from tailings slurry of gold mine treatment plant by alkali fusion technique, IJCEBS, Vol.1, Issue 2, ISSN 2320-4087, hal. 211-212. 